\title{
Communication \\ Effect of Magnesium Ion on the Radical-Scavenging Rate of Pterostilbene in an Aprotic Medium: Mechanistic Insight into the Antioxidative Reaction of Pterostilbene
}

\author{
Ikuo Nakanishi ${ }^{1, *(\mathbb{D}}$, Yoshimi Shoji ${ }^{1,2}$, Kei Ohkubo ${ }^{1,3, * \mathbb{D}}$, Megumi Ueno ${ }^{2}$, Kei Shimoda ${ }^{4}$ \\ Ken-ichiro Matsumoto ${ }^{2}$ (D), Kiyoshi Fukuhara ${ }^{5, *(D)}$ and Hiroki Hamada ${ }^{6, *}$
}

Citation: Nakanishi, I.; Shoji, Y.; Ohkubo, K.; Ueno, M.; Shimoda, K.; Matsumoto, K.-i.; Fukuhara, K.; Hamada, H. Effect of Magnesium Ion on the Radical-Scavenging Rate of Pterostilbene in an Aprotic Medium: Mechanistic Insight into the Antioxidative Reaction of Pterostilbene. Antioxidants 2022, 11, 340. https://doi.org/10.3390/ antiox 11020340

Academic Editor: Nino Russo

Received: 13 January 2022

Accepted: 7 February 2022

Published: 9 February 2022

Publisher's Note: MDPI stays neutral with regard to jurisdictional claims in published maps and institutional affiliations.

Copyright: (C) 2022 by the authors. Licensee MDPI, Basel, Switzerland. This article is an open access article distributed under the terms and conditions of the Creative Commons Attribution (CC BY) license (https:// creativecommons.org/licenses/by/ $4.0 /)$.
1 Quantum RedOx Chemistry Group, Institute for Quantum Life Science (iQLS), Quantum Life and Medical Science Directorate, National Institutes for Quantum Science and Technology (QST), Inage-ku, Chiba 263-8555, Japan; shoji.yoshimi@qst.go.jp

2 Quantitative RedOx Sensing Group, Department of Radiation Regulatory Science Research, National Institute of Radiological Sciences (NIRS), Quantum Life and Medical Science Directorate, National Institutes for Quantum Science and Technology (QST), Inage-ku, Chiba 263-8555, Japan; ueno.megumi@qst.go.jp (M.U.); matsumoto.kenichiro@qst.go.jp (K.-i.M.)

3 Institute for Advanced Co-Creation Studies, Open and Transdisciplinary Research Initiatives, Osaka University, 2-8 Yamada-oka, Suita, Osaka 565-0871, Japan

4 Department of Biomedical Chemistry, Faculty of Medicine, Oita University, Yufu City, Oita 879-5593, Japan; shimoda@oita-u.ac.jp

5 School of Pharmacy, Showa University, Shinagawa-ku, Tokyo 142-8555, Japan

6 Department of Life Science, Okayama University of Science, Kita-ku, Okayama 700-0005, Japan

* Correspondence: nakanishi.ikuo@qst.go.jp (I.N.); ohkubo@irdd.osaka-u.ac.jp (K.O.); fukuhara@pharm.showa-u.ac.jp (K.F.); hamada@dls.ous.ac.jp (H.H.)

\begin{abstract}
Pterostilbene (PTS), a methylated analog of resveratrol (RSV), has recently attracted much attention due to its enhanced bioavailability compared to RSV. However, little is known about the radical-scavenging mechanism of PTS. In this study, we investigated the effect of $\mathrm{Mg}\left(\mathrm{ClO}_{4}\right)_{2}$ on the scavenging reaction of galvinoxyl radical $\left(\mathrm{GO}^{\bullet}\right)$ by PTS in acetonitrile $(\mathrm{MeCN})$. GO ${ }^{\bullet}$ was used as a model for reactive oxygen radicals. The second-order rate constant $\left(k_{\mathrm{H}}\right)$ for the GO${ }^{\bullet}$ scavenging reaction by PTS was more than threefold larger than that by RSV, although thermodynamic parameters, such as the relative $\mathrm{O}-\mathrm{H}$ bond dissociation energies of the phenolic $\mathrm{OH}$ groups, ionization potentials, and HOMO energies calculated by the density functional theory are about the same between PTS and RSV. The oxidation peak potential of PTS determined by the cyclic voltammetry in $\mathrm{MeCN}\left(0.10 \mathrm{M} \mathrm{Bu}_{4} \mathrm{NClO}_{4}\right)$ was also virtually the same as that of RSV. On the other hand, no effect of $\mathrm{Mg}\left(\mathrm{ClO}_{4}\right)_{2}$ on the $k_{\mathrm{H}}$ values was observed for PTS, in contrast to the case for RSV. A kinetic isotope effect of 3.4 was observed when PTS was replaced by a deuterated PTS. These results suggest that a one-step hydrogen-atom transfer from PTS to GO ${ }^{\bullet}$ may be the rate-determining step in MeCN.
\end{abstract}

Keywords: antioxidant; hydrogen transfer; resveratrol; pterostilbene; galvinoxyl; magnesium ion; kinetic isotope effect; density functional theory; cyclic voltammetry

\section{Introduction}

Resveratrol (RSV) (Figure 1), 3,5,4'-trihydroxy-trans-stilbene, found in grapes, is one of the representative antioxidants that shows a plethora of remarkable biological properties [1]. On the other hand, pterostilbene (PTS) (Figure 1), where the phenolic OH groups at the C-3 and C -5 positions in RSV are replaced by methoxy groups, has recently attracted much attention due to its enhanced bioavailability, compared to RSV [2-6]. However, little is known about the radical-scavenging mechanism of PTS. There are three mechanisms for the initial step of the radical-scavenging reaction of phenolic antioxidants: one-step hydrogenatom transfer (HAT) from the phenolic $\mathrm{OH}$ group; electron transfer followed by proton transfer (ET-PT); and sequential proton-loss electron transfer (SPLET) [7]. Redox-inactive 
metal ions, such as magnesium ion $\left(\mathrm{Mg}^{2+}\right)$, are a powerful tool to examine the involvement of electron-transfer processes [8-13], because it has been reported that electron-transfer reactions are significantly accelerated by their presence $[14,15]$. The stabilization of oneelectron reduced species by these metal ions leads to the acceleration. In fact, a significant acceleration in the radical-scavenging reaction of RSV or (+)-catechin was observed in the presence of $\mathrm{Mg}^{2+}$ in acetonitrile $(\mathrm{MeCN})$, suggesting that the reaction may proceed via the ET-PT mechanism [8,12]. In MeCN, an aprotic solvent, the SPLET mechanism can be ruled out, since the deprotonation of the phenolic $\mathrm{OH}$ group hardly occurs.<smiles>[R6]c1cc(O)cc(/C=C/c2ccc(O)cc2)c1</smiles>

Figure 1. Chemical structures of RSV and PTS.

On the other hand, no effect of $\mathrm{Mg}^{2+}$ was observed on the radical-scavenging rate of a vitamin $\mathrm{E}$ analog in $\mathrm{MeCN}$, suggesting that the reaction may proceed via the HAT mechanism [13]. The elucidation of the detailed radical-scavenging mechanism is of considerable importance for the development of synthetic antioxidants having a stronger activity than naturally occurring ones. In fact, we have previously reported a number of synthetic antioxidants that show a stronger radical-scavenging activity than the parent compounds [16-31]. We report herein the effect of $\mathrm{Mg}^{2+}$ on the scavenging reaction of galvinoxyl radical $\left(\mathrm{GO}^{\bullet}\right)$ by $\mathrm{PTS}$ in $\mathrm{MeCN}$. GO ${ }^{\bullet}$ is frequently used as a model for the reactivity of reactive oxygen species to evaluate the activity of antioxidants [32]. The difference in the effect of $\mathrm{Mg}^{2+}$ on the $\mathrm{GO}^{\bullet}$-scavenging rates between RSV and PTS provides a valuable insight into the structure-activity and structure-mechanism relationships for the radical-scavenging reaction of phenolic antioxidants.

\section{Materials and Methods}

\subsection{Materials}

PTS (analytical grade) was commercially obtained from Excel Chemical Co., Ltd., Tokyo, Japan, and used without further purification. $\mathrm{GO}^{\bullet}$ was purchased from the Tokyo Chemical Industry Co., Ltd., Tokyo, Japan. MeCN (spectral grade) used as a solvent was commercially obtained from Nacalai Tesque, Inc., Kyoto, Japan, and used as received. Mg $\left(\mathrm{ClO}_{4}\right)_{2}$ was purchased from FUJIFILM Wako Pure Chemical Corporation, Osaka, Japan. Deuterated PTS was prepared by dissolving $1 \mathrm{~g}$ of PTS in $20 \mathrm{~mL}$ of $10 \% \mathrm{D}_{2} \mathrm{O}$ in $\mathrm{CD}_{3} \mathrm{OD}$ and then removing the solvent by evaporation, a process that was repeated three times (99\% deuteration degree for NMR spectroscopy). RSV was commercially obtained from Sigma-Ardrich, St. Louis, MO, USA). Tetra- $n$-butylammonium perchlorate $\left(\mathrm{Bu}_{4} \mathrm{NClO}_{4}\right)$, used as a supporting electrolyte for electrochemical measurements, was purchased from the Tokyo Chemical Industry Co., Ltd., Japan, recrystallized from ethanol (spectral grade, Nacalai Tesque, Inc., Kyoto, Japan), and dried under vacuum at $313 \mathrm{~K}$.

\subsection{Spectral and Kinetic Measurements}

UV-vis spectra were recorded on an Agilent 8453 photodiode array spectrophotometer (Agilent Technologies, Santa Clara, CA, USA). The GO ${ }^{\bullet}$-scavenging rates of PTS in MeCN were determined based on the absorbance change at $428 \mathrm{~nm}$ due to $\mathrm{GO}^{\bullet}\left(\varepsilon=1.4 \times 10^{5} \mathrm{M}^{-1} \mathrm{~cm}^{-1}\right)$ every $1.5 \mathrm{~s}$ after mixing of $0.2 \mathrm{~mL}$ of an MeCN solution of $\mathrm{GO}^{\bullet}\left(2.0 \times 10^{-5} \mathrm{M}\right)$ with $0.2 \mathrm{~mL}$ of an MeCN solution containing PTS $\left(3.0 \times 10^{-3}, 5.9 \times 10^{-3}, 8.9 \times 10^{-3}\right.$, and $\left.1.2 \times 10^{-2} \mathrm{M}\right)$, using a 
stopped-flow technique on a UNISOKU RSP-1000-02NM spectrophotometer (UNISOKU Co., Ltd., Osaka, Japan), which was thermostated at $298 \mathrm{~K}$ with a Thermo Scientific NESLAB RTE-7 Circulating Bath (Thermo Fisher Scientific, Inc., Waltham, MA, USA). Pseudo-first-order rate constants $\left(k_{\text {obs }}\right)$ were determined by a least-square curve fit on an Apple MacBook Pro personal computer (Apple Inc., Cupertino, CA, USA). The first-order plots of $\ln \left(A-A_{\infty}\right)$ vs. time $(A$ and $A_{\infty}$ are the absorbance at the reaction time and the final absorbance, respectively) were linear until three or more half-lives with the correlation coefficient $\rho>0.999$. It was confirmed that the $k_{\text {obs }}$ values derived from at least three independent measurements agreed within an experimental error of $\pm 5 \%$ in each case.

\subsection{Theoretical Calculations}

Density functional theory (DFT) calculations were performed on a 16-processor high performance computer (ForScientist XD1, HPC System Inc., Tokyo, Japan). The geometry optimization was performed using the M06-2X/6-31++G(d) basis set with a C-PCM solvation model parameterized for acetonitrile, as implemented in the Gaussian 09 (Revision A.02, Gaussian, Inc., Wallingford, CT, USA) (the computational details (coordinates and energy values) are available in the Supplementary Materials) [33]. The calculated energy difference values ( $D_{\mathrm{HT}}, \mathrm{HT}$ : hydrogen transfer) are defined as the energy difference values of heat of formations of phenoxyl radicals $(\Delta H$ (phenoxyl radical)) and the parent phenols $(\Delta H$ (phenol)) (Equation (1)), while the bond dissociation energy (BDE) includes the heat of formation of hydrogen atom $\left(\Delta H\left(\mathrm{H}^{\bullet}\right)\right)$ (Equation 2). The ionization potentials (IP) were calculated from the energy difference between the phenol and the corresponding radical cation.

$$
\begin{gathered}
D_{\mathrm{HT}}=\Delta H(\text { phenoxyl radical })-\Delta H(\text { phenol }) \\
\mathrm{BDE}=D_{\mathrm{HT}}+\Delta H\left(\mathrm{H}^{\bullet}\right)
\end{gathered}
$$

\subsection{Electrochemical Measurements}

The cyclic voltammetry measurements were performed on an ALS-630A electrochemical analyzer (BAS Co. Ltd., Tokyo, Japan) in $\mathrm{MeCN}$ containing $0.10 \mathrm{M} \mathrm{Bu}_{4} \mathrm{NClO}_{4}$ as a supporting electrolyte. The Pt working electrode (BAS Co. Ltd., Tokyo, Japan) was polished with an alumina polishing suspension (BAS Co. Ltd., Tokyo, Japan) and an alumina polishing pad (BAS Co. Ltd., Tokyo, Japan) and rinsed with methanol (FUJIFILM Wako Pure Chemical Corporation, Osaka, Japan) before use. The counter electrode was a platinum wire (BAS Co. Ltd., Tokyo, Japan). The concentration of PTS or RSV was $1.0 \times 10^{-3} \mathrm{M}$. The measured potentials were recorded with respect to an $\mathrm{Ag} / \mathrm{AgNO}_{3}(0.01 \mathrm{M})$ reference electrode (BAS Co. Ltd., Tokyo, Japan) with the sweep rate of $100 \mathrm{mV} \mathrm{s}^{-1}$ at $298 \mathrm{~K}$. The oxidation peak potentials $\left(E_{\mathrm{pa}}\right)$ were converted to those vs. the saturated calomel electrode (SCE) by adding $0.29 \mathrm{~V}$ [34].

\section{Results and Discussion}

The rate of the reaction of PTS with $\mathrm{GO}^{\bullet}$ was investigated by monitoring the spectral change during the reaction. Upon mixing of PTS with $\mathrm{GO}^{\bullet}$ in $\mathrm{MeCN}$, the absorption band at $428 \mathrm{~nm}$ due to $\mathrm{GO}^{\bullet}$ decreased gradually, as shown in Figure 2 . This indicates that PTS efficiently scavenged $\mathrm{GO}^{\bullet}$ (Figure 3 ). The decay of the absorbance at $428 \mathrm{~nm}$ monitored by a stopped-flow technique obeyed pseudo-first-order kinetics, when the concentration of PTS ([PTS]) was maintained at more than a 10-fold excess of the concentration of GO (inset of Figure 2$)$. The pseudo-first-order rate constants $\left(k_{\text {obs }}\right)$ linearly increased with increasing [PTS] (Figure 4$)$. The second-order rate constant $\left(k_{\mathrm{H}}\right)$ in Equation 3 could be determined from the slope of the plot (Equation 4 ) for the $\mathrm{GO}^{\bullet}$-scavenging reaction by PTS (Figure 3 ) in $\mathrm{MeCN}$ to be $1.3 \times 10 \mathrm{M}^{-1} \mathrm{~s}^{-1}$. This $k_{\mathrm{H}}$ value is more than threefold larger than that obtained for RSV $\left(k_{\mathrm{H}}=4.1 \mathrm{M}^{-1} \mathrm{~s}^{-1}\right)$ under the same experimental conditions (Table 1) [8].

$$
-\mathrm{d}\left[\mathrm{GO}^{\bullet}\right] / \mathrm{d} t=k_{\mathrm{H}}[\mathrm{PTS}]\left[\mathrm{GO}^{\bullet}\right]
$$




$$
k_{\text {obs }}\left([\mathrm{PTS}]>10\left[\mathrm{GO}^{\bullet}\right]\right)=k_{\mathrm{H}}[\mathrm{PTS}]
$$

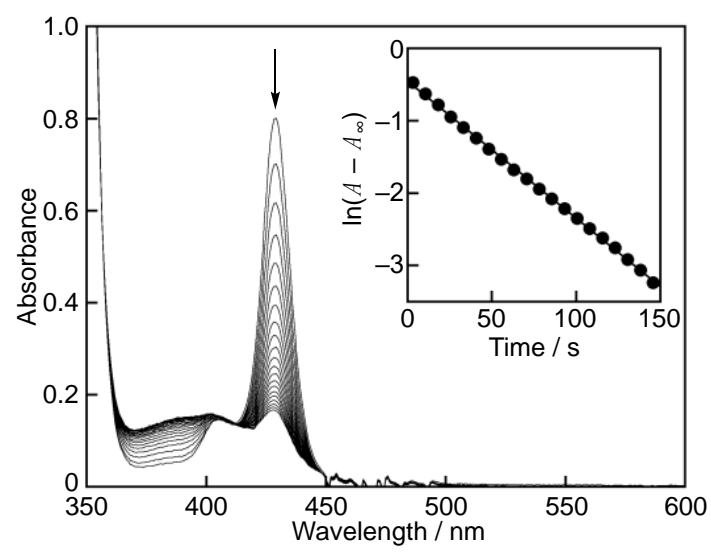

Figure 2. Spectral change observed every $7.5 \mathrm{~s}$ (once every fifth measurement) during the reaction of PTS $\left(1.5 \times 10^{-3} \mathrm{M}\right)$ with GO $\left(1.0 \times 10^{-5} \mathrm{M}\right)$ in MeCN at $298 \mathrm{~K}$. Inset: the first-order plot of the absorbance at $428 \mathrm{~nm}$.<smiles>COc1cc(/C=C/c2ccc(O)cc2)cc(OC)c1</smiles><smiles>COc1cc(/C=C/c2ccc(Cl)cc2)cc(OC)c1</smiles>

Figure 3. Hydrogen transfer from PTS to GO ${ }^{\bullet}$.

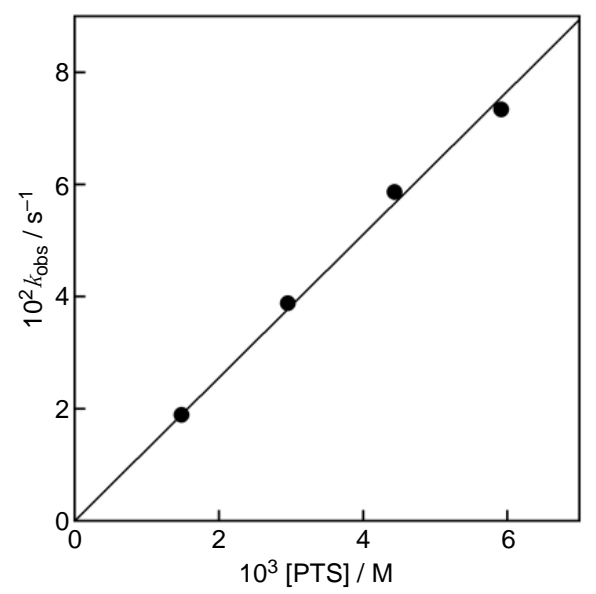

Figure 4. Plots of $k_{\mathrm{obs}}$ vs. concentrations of PTS. 
Table 1. Experimental $k_{\mathrm{H}}$ values in $\mathrm{MeCN}$, calculated $D_{\mathrm{HT}}$, IP and $E_{\mathrm{HOMO}}$ values by DFT, and experimental $E_{\mathrm{pa}}$ values in $\mathrm{MeCN}\left(0.10 \mathrm{M} \mathrm{Bu}_{4} \mathrm{NClO}_{4}\right)$ for RSV and PTS.

\begin{tabular}{|c|c|c|c|c|c|}
\hline Compound & $k_{\mathrm{H}} / \mathbf{M}^{-1} \mathrm{~s}^{-1}$ & $D_{\mathrm{HT}} / \mathrm{kcal} \mathrm{mol}^{-1}$ & IP/kcal mol-1 & $E_{\text {HOMO }} / \mathrm{kcal} \mathrm{mol}^{-1}$ & $E_{\mathrm{pa}} / \mathrm{V}$ vs. SCE \\
\hline RSV & 4.1 & 398.4 & 133.3 & -157.7 & +1.10 \\
\hline PTS & $1.3 \times 10$ & 398.2 & 132.6 & -158.9 & +1.11 \\
\hline
\end{tabular}

The $k_{\mathrm{H}}$ values were also determined for the reaction of PTS with $\mathrm{GO} \bullet$ in the presence of $\mathrm{Mg}\left(\mathrm{ClO}_{4}\right)_{2}$ to examine whether the electron-transfer reaction is involved as the ratedetermining step. In the case of RSV, the $k_{\mathrm{H}}$ values were reported to increase with increasing the concentration of $\mathrm{Mg}\left(\mathrm{ClO}_{4}\right)_{2}$ [8]. Such an acceleration by $\mathrm{Mg}\left(\mathrm{ClO}_{4}\right)_{2}$ indicates that the $\mathrm{GO}^{\bullet}$-scavenging reaction by $\mathrm{RSV}$ proceeds via an electron transfer from RSV to GO ${ }^{\bullet}$ as the rate-determining step in $\mathrm{MeCN}$ [8]. On the other hand, no acceleration effect of $\mathrm{Mg}\left(\mathrm{ClO}_{4}\right)_{2}$ was observed on the $k_{\mathrm{H}}$ values for PTS, as shown in Figure 5. Thus, the GO ${ }^{\bullet}$-scavenging reaction by PTS may proceed via the one-step hydrogen-atom transfer rather than via the electron transfer followed by proton transfer as the rate-determining step in MeCN.

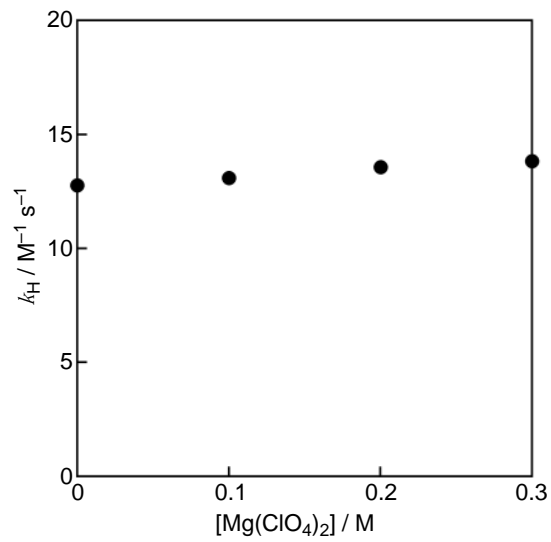

Figure 5. Plots of $k_{\mathrm{H}}$ vs. concentrations of $\mathrm{Mg}\left(\mathrm{ClO}_{4}\right)_{2}$.

The deuterium primary kinetic isotope effect (KIE) was investigated with the use of a deuterated pterostilbene (PTS- $d$ ), which was prepared by the exchange reaction of $\mathrm{H}^{+}$with $\mathrm{D}^{+}$ in the phenolic $\mathrm{OH}$ group of PTS in deuterated methanol $\left(\mathrm{CH}_{3} \mathrm{OD}\right)$. The second-order rate constant $\left(k_{\mathrm{D}}\right)$ for the reaction of PTS- $d$ with $\mathrm{GO}^{\bullet}$ was determined to be $3.7 \mathrm{M}^{-1} \mathrm{~s}^{-1}$. Thus, the KIE value $\left(k_{\mathrm{H}} / k_{\mathrm{D}}\right)$ was calculated to be 3.4 . A KIE value larger than unity $\left(k_{\mathrm{H}} / k_{\mathrm{D}}>1\right)$ clearly supports the involvement of a hydrogen-atom transfer as the rate-determining step [35].

The density functional theory (DFT) calculations were also carried out to compare the radical-scavenging reactivity of PTS with RSV [33]. The energy difference values $\left(D_{\mathrm{HT}}\right.$, HT: hydrogen transfer) between the parent phenols (RSV and PTS) and the corresponding phenoxyl radicals were determined by DFT calculation at the M06-2X/6-31++G(d) level with C-PCM = acetonitrile. The $D_{\mathrm{HT}}$ values reflect the relative $\mathrm{O}-\mathrm{H}$ bond dissociation energies of the phenolic $\mathrm{OH}$ groups. Thus, the hydrogen-atom donor ability of the phenolic $\mathrm{OH}$ groups can be evaluated by the $D_{\mathrm{HT}}$ values. The calculated $D_{\mathrm{HT}}$ value thus obtained for the OH group at the C-4' position in PTS (398.2 $\left.\mathrm{kcal} \mathrm{mol}^{-1}\right)$ is about the same as that in RSV (398.4 kcal mol${ }^{-1}$ ) (Table 1). On the other hand, the electron donor ability of the phenols can be evaluated by their ionization potentials (IP). The IP value of PTS was also calculated by DFT calculation to be $132.6 \mathrm{kcal} \mathrm{mol}^{-1}$, which is also about the same as that of RSV (133.3 $\mathrm{kcal} \mathrm{mol}^{-1}$ ) (Table 1$)$. The HOMO energies ( $\left.E_{\mathrm{HOMO}}\right)$ of PTS and RSV were also calculated by the DFT calculations, as shown in Table 1, and were also almost the same. The energy difference of the HOMO energies $\left(0.8 \mathrm{kcal} \mathrm{mol}^{-1}\right)$ is virtually the same as that of the IP values $\left(0.8 \mathrm{kcal} \mathrm{mol}^{-1}\right)$.

The electron donor ability of PTS was also compared with RSV by cyclic voltammetry measurements in $\mathrm{MeCN}$ containing $0.10 \mathrm{M} \mathrm{Bu}_{4} \mathrm{NClO}_{4}$ as a supporting electrolyte. An irreversible oxidation (anordic) peak was observed both for PTS and RSV, as shown in 
Figure 6. From the cyclic voltammograms, the oxidation peak potentials $\left(E_{\mathrm{pa}}\right)$ of PTS and RSV were determined to be +1.11 and $+1.10 \mathrm{~V}$ vs. SCE at the scan rate of $100 \mathrm{mV} \mathrm{s}^{-1}$ (Table 1). These $E_{\text {pa }}$ values are also virtually the same, indicating that the electron donor ability of PTS is almost the same as that of RSV in $\mathrm{MeCN}\left(0.10 \mathrm{M} \mathrm{Bu}_{4} \mathrm{NClO}_{4}\right)$.

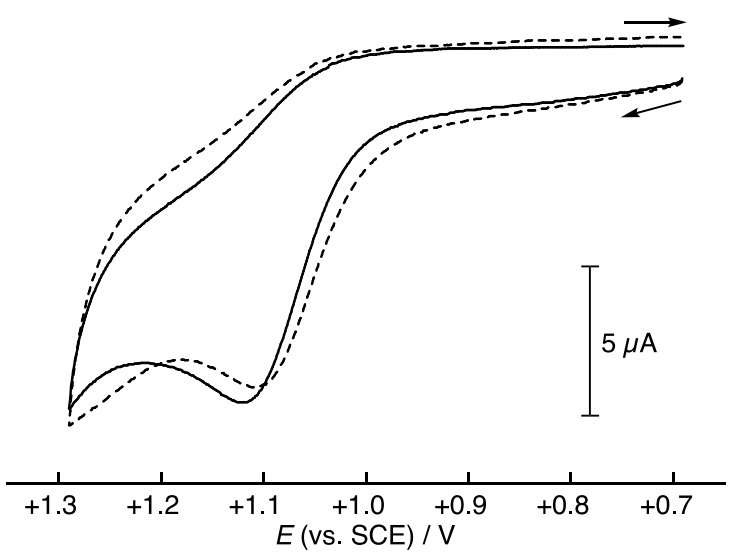

Figure 6. Cyclic voltammograms of PTS $\left(1.0 \times 10^{-3} \mathrm{M}\right)$ (solid line) and RSV $\left(1.0 \times 10^{-3} \mathrm{M}\right)$ (dashed line) in $\mathrm{MeCN}\left(0.10 \mathrm{M} \mathrm{Bu}_{4} \mathrm{NClO}_{4}\right)$ recorded at the scan rate of $100 \mathrm{mV} \mathrm{s}^{-1}$ on a Pt working electrode.

The partition coefficient of PTS $(\log P=2.69)$ is significantly larger than that of RSV $(\log P=2.048)$ [3]. Thus, the hydrophobic interaction between PTS and GO ${ }^{\bullet}$ is thought to be stronger than that between $\mathrm{RSV}$ and $\mathrm{GO}^{\bullet}$ in $\mathrm{MeCN}$, an aprotic polar solvent, although such an interaction could not be observed experimentally. This may cause the faster $\mathrm{GO}^{\bullet}$-scavenging rate for PTS compared to RSV.

\section{Conclusions}

PTS scavenged GO ${ }^{\bullet}$ more rapidly than RSV. The methyl substitution of the phenolic $\mathrm{OH}$ groups in RSV may result in the change in the $\mathrm{GO}^{\bullet}$-scavenging mechanism from electron transfer to the one-step hydrogen-atom transfer, providing valuable information about the structure-reactivity and structure-mechanism relationships for the radical-scavenging reaction of phenolic antioxidants.

Supplementary Materials: The following are available online at https:/ /www.mdpi.com/article/10 $.3390 /$ antiox11020340/s1. The computational details (coordinates and energy values).

Author Contributions: Conceptualization, I.N.; methodology, I.N., K.O., K.F. and H.H.; formal analysis, Y.S. and K.O.; investigation, I.N., Y.S., K.O., M.U., K.S. and K.F.; data curation, Y.S., K.O. and K.F.; writing - original draft preparation, I.N.; writing—review and editing, K.O., K.-i.M. and K.F.; supervision, I.N., K.O., K.-i.M., K.F. and H.H.; project administration, I.N.; funding acquisition, I.N. All authors have read and agreed to the published version of the manuscript.

Funding: This work was partially supported by Grant-in-Aid (No. JP18K06620 to I.N., JP20H02779, JP20H04819, JP18H04650, JP17H03010, and JP16H02268 to K.O.) from the Ministry of Education, Culture, Sports, Science and Technology, Japan.

Institutional Review Board Statement: Not applicable.

Informed Consent Statement: Not applicable.

Data Availability Statement: Data is contained within the article.

Conflicts of Interest: The authors declare no conflict of interest.

\section{References}

1. Meng, X.; Zhou, J.; Zhao, C.-N.; Gan, R.-Y.; Li, H.-B. Health benefits and molecular mechanisms of resveratrol: A narrative review. Foods 2020, 9, 340. [CrossRef] [PubMed] 
2. Koh, Y.; Ho, C.; Pan, M. Recent advances in health benefits of stilbenoids. J. Agric. Food Chem. 2021, 69, 10036-10057. [CrossRef] [PubMed]

3. Kim, H.; Seo, H.; Yokoyama, W. Chemistry of pterostilbene and its metabolic effects. J. Agric. Food Chem. 2020, 68, 12836-12841. [CrossRef] [PubMed]

4. Ma, Z.; Zhang, X.; Xu, L.; Liu, D.; Di, S.; Li, W.; Zhang, J.; Zhang, H.; Li, X.; Han, J.; et al. Pterostilbene: Mechanisms of its action as oncostatic agent in cell models and in vivo studies. Pharmacol. Res. 2019, 145, 104265. [CrossRef]

5. Kapetanovic, I.M.; Muzzio, M.; Huang, Z.H.; Thompson, T.N.; McCormick, D.L. Pharmacokinetics, oral bioavailability, and metabolic profile of resveratrol and its dimethylether analog, pterostilbene, in rats. Cancer Chemother. Pharmacol. 2011, 68, 593-601. [CrossRef]

6. McCormack, D.; McFadden, D. A review of pterostilbene antioxidant activity and disease modification. Oxid. Med. Cell. Longev. 2013, 2013, 575482. [CrossRef]

7. Pandithavidana, D.R.; Jayawardana, S.B. Comparative study of antioxidant potential of selected dietary vitamins; computational insights. Molecules 2019, 24, 1646. [CrossRef]

8. Nakanishi, I.; Shimada, T.; Ohkuob, K.; Manda, S.; Shimizu, T.; Urano, S.; Okuda, H.; Miyata, N.; Ozawa, T.; Anzai, K.; et al. Involvement of electron transfer in the radical-scavenging reaction of resveratrol. Chem. Lett. 2007, 36, 1276-1277. [CrossRef]

9. Nakanishi, I.; Kawashima, T.; Ohkubo, K.; Kanazawa, H.; Inami, K.; Mochizuki, M.; Fukuahra, K.; Okuda, H.; Ozawa, T.; Itoh, S.; et al. Electron-transfer mechanism in radical-scavenging reactions by a vitamin E model in a protic medium. Org. Biomol. Chem. 2005, 3, 626-629. [CrossRef]

10. Nakanishi, I.; Ohkubo, K.; Miyazaki, K.; Hakamata, W.; Urano, S.; Ozawa, T.; Okuda, H.; Fukuzumi, S.; Ikota, N.; Fukuhara, K. A planar catechin analogue having a more negative oxidation potential than (+)-catechin as an electron-transfer antioxidant against a peroxyl radical. Chem. Res. Toxicol. 2004, 17, 26-31. [CrossRef]

11. Nakanishi, I.; Uto, Y.; Ohkubo, K.; Miyazaki, K.; Yakumaru, H.; Urano, S.; Okuda, H.; Ueda, J.; Ozawa, T.; Fukuhara, K.; et al. Efficient radical scavenging ability of artepillin C, a major component of Brazilian propolis, and the mechanism. Org. Biomol. Chem. 2003, 1, 1452-1454. [CrossRef] [PubMed]

12. Nakanishi, I.; Miyazaki, K.; Shimada, T.; Ohkubo, K.; Urano, S.; Ikota, N.; Ozawa, T.; Fukuzumi, S.; Fukuhara, K. Effects of metal ions distinguishing between one-step hydrogen- and electron-transfer mechanisms for the radical-scavenging reaction of (+)-catechin. J. Phys. Chem. A 2002, 106, 11123-11126. [CrossRef]

13. Nakanishi, I.; Fukuhara, K.; Shimada, T.; Ohkubo, K.; Iizuka, Y.; Inami, K.; Mochizuki, M.; Urano, S.; Itoh, S.; Miyata, N.; et al Effects of magnesium ion on kinetic stability and spin distribution of phenoxyl radical derived from a vitamin E analogue; mechanistic insight into antioxidative hydrogen transfer reaction of vitamin E. J. Chem. Soc. Perkin Trans. 22002 , 1520-1524. [CrossRef]

14. Fukuzumi, S.; Ohkubo, K. Metal ion-coupled and decoupled electron transfer. Coord. Chem. Rev. 2010, 254, 372-385. [CrossRef]

15. Fukuzumi, S.; Ohkubo, K.; Morimoto, Y. Mechanism of metal ion-coupled electron transfer. Phys. Chem. Chem. Phys. 2012, 14, 8472-8484. [CrossRef] [PubMed]

16. Imai, K.; Nakanishi, I.; Ohkubo, K.; Ohno, A.; Mizuno, M.; Fukuzumi, S.; Matsumoto, K.; Fukuhara, K. Synthesis and radicalscavenging activity of C-methylated fisetin analogues. Bioorg. Med. Chem. 2019, 27, 1720-1727. [CrossRef]

17. Sekine-Suzuki, E.; Nakanishi, I.; Imai, K.; Ueno, M.; Shimokawa, T.; Matsumoto, K.; Fukuhara, K. Efficient protective activity of a planar catechin analogue against radiation-induced apoptosis in rat thymocytes. RSC Adv. 2018, 8, 10158-10162. [CrossRef]

18. Mizuno, M.; Nakanishi, I.; Matsumoto, K.; Fukuhara, K. Enhanced radical scavenging activity of a procyanidin B3 analogue comprised of a dimer of planar catechin. Bioorg. Med. Chem. Lett. 2017, 27, 5010-5013. [CrossRef]

19. Imai, K.; Nakanishi, I.; Ohkubo, K.; Ohba, Y.; Arai, T.; Mizuno, M.; Fukuzumi, S.; Matsumoto, K.; Fukuhara, K. Synthesis of methylated quercetin analogues for enhancement of radical-scavenging activity. RSC Adv. 2017, 7, 17968-17979. [CrossRef]

20. Mizuno, M.; Nakanishi, I.; Matsubayashi, S.; Imai, K.; Arai, T.; Matsumoto, K.; Fukuhara, K. Synthesis and antioxidant activity of a procyanidin B3 analogue. Bioorg. Med. Chem. Lett. 2017, 27, 1041-1044. [CrossRef]

21. Uzura, S.; Sekine-Suzuki, E.; Nakanishi, I.; Sonoda, M.; Tanimori, S. A facile and rapid access to resveratrol derivatives and their radioprotective activity. Bioorg. Med. Chem. Lett. 2016, 26, 3886-3891. [CrossRef] [PubMed]

22. Imai, K.; Nakanishi, I.; Ohno, A.; Kurihara, M.; Miyata, N.; Matsumoto, K.; Nakamura, A.; Fukuhara, K. Synthesis and radical-scavenging activity of a dimethylcatechin analogue. Bioorg. Med. Chem. Lett. 2014, 24, 2582-2584. [CrossRef] [PubMed]

23. Inami, K.; Nakanishi, I.; Morita, M.; Furukawa, M.; Ohkubo, K.; Fukuzumi, S.; Mochizuki, M. The high stability of intermediate radicals enhances the radical-scavenging activity of aminochromanols. RSC Adv. 2012, 2, 12714-12717. [CrossRef]

24. Kawashima, T.; Manda, S.; Uto, Y.; Ohkubo, K.; Hori, H.; Matsumoto, K.; Fukuhara, K.; Ikota, N.; Fukuzumi, S.; Ozawa, T.; et al. Kinetic and mechanism for the scavenging reaction of the 2,2-diphenyl-1-picrylhydrazyl radical by synthetic artepillin $\mathrm{C}$ analogues. Bull. Chem. Soc. Jpn. 2012, 85, 877-883. [CrossRef]

25. Imai, K.; Nakanishi, I.; Anzai, K.; Ozawa, T.; Miyata, N.; Urano, S.; Okuda, H.; Nakamura, A.; Fukuhara, K. Synthesis and enhanced radical scavenging activity of a conformationally constrained epigallocatechin analogue. Chem. Lett. 2011, 40, 1417-1419. [CrossRef]

26. Fukuhara, K.; Ohno, A.; Nakanishi, I.; Imai, K.; Nakamura, A.; Anzai, K.; Miyata, N.; Okuda, H. Novel ninhydrin adduct of catechin with potent antioxidantive activity. Tetrahedron Lett. 2009, 50, 6989-6992. [CrossRef] 
27. Fukuhara, K.; Nakanishi, I.; Ohkubo, K.; Obara, Y.; Tada, A.; Imai, K.; Ohno, A.; Nakamura, A.; Ozawa, T.; Urano, S.; et al. Intramolecular base-accelerated radical-scavenging reaction of a planar catechin derivative bearing a lysine moiety. Chem. Commun. 2009, 6180-6182. [CrossRef]

28. Fukuhara, K.; Nakanishi, I.; Matsuoka, A.; Matsumura, T.; Honda, S.; Hayashi, M.; Ozawa, T.; Miyata, N.; Saito, S.; Ikota, N.; et al. Effect of methyl substitution on antioxidantive property and genotoxicity of resveratrol. Chem. Res. Toxicol. 2008, $21,282-287$. [CrossRef]

29. Manda, S.; Nakanishi, I.; Ohkubo, K.; Uto, Y.; Kawashima, T.; Fukuhara, K.; Okuda, H.; Hori, H.; Ozawa, T.; Ikota, N.; et al. Enhanced radical-scavenging activity of naturally-oriented artepillin C derivatives. Chem. Commun. 2008, 626-628. [CrossRef]

30. Hakamata, W.; Nakanishi, I.; Masuda, Y.; Shimizu, T.; Higuchi, H.; Nakamura, Y.; Saito, S.; Urano, S.; Oku, T.; Ozawa, T.; et al. Planar catechin analogue with alkyl side chains, a potent antioxidant and an $\alpha$-glucosidase inhibitor. J. Am. Chem. Soc. 2006, 128, 6524-6525. [CrossRef]

31. Fukuhara, K.; Nakanishi, I.; Kansui, H.; Sugiyama, E.; Kimura, M.; Shimada, T.; Urano, S.; Yamaguchi, K.; Miyata, N. Enhanced radical-scavenging activity of a planar catechin analogue. J. Am. Chem. Soc. 2002, 124, 5952-5953. [CrossRef] [PubMed]

32. Shi, H.; Noguchi, N.; Niki, E. Galvinoxyl method for standardizing electron and proton donation activity. Methods Enzymol. 2001, 335, 157-166. [PubMed]

33. Frisch, M.J.; Trucks, G.W.; Schlegel, H.B.; Scuseria, G.E.; Robb, M.A.; Cheeseman, J.R.; Scalmani, G.; Barone, V.; Mennucci, B.; Petersson, G.A.; et al. Gaussian 09; Gaussian, Inc.: Wallingford, CT, USA, 2009.

34. Mann, C.K.; Barnes, K.K. Electrochemical Reactions in Nonaqueous Systems; Mercel Dekker: New York, NY, USA, 1970.

35. Fukuzumi, S.; Lee, Y.; Nam, W. Deuterium kinetic isotope effects as redox mechanistic criterions. Bull. Korean Chem. Soc. 2021, 42, 1558-1568. [CrossRef] 